\title{
Essential interventions for child health
}

\author{
Zohra S Lassi, Dania Mallick, Jai K Das, Lekho Mal, Rehana A Salam, Zulfiqar A Bhutta*
}

\begin{abstract}
Child health is a growing concern at the global level, as infectious diseases and preventable conditions claim hundreds of lives of children under the age of five in low-income countries. Approximately 7.6 million children under five years of age died in 2011, calculating to about 19000 children each day and almost 800 every hour. About 80 percent of the world's under-five deaths in 2011 occurred in only 25 countries, and about half in only five countries: India, Nigeria, Democratic Republic of the Congo, Pakistan and China. The implications and burden of such statistics are huge and will have dire consequences if they are not corrected promptly. This paper reviews essential interventions for improving child health, which if implemented properly and according to guidelines have been found to improve child health outcomes, as well as reduce morbidity and mortality rates. It also includes caregivers and delivery strategies for each intervention. Interventions that have been associated with a decrease in mortality and disease rates include exclusive breastfeeding, complementary feeding strategies, routine immunizations and vaccinations for children, preventative zinc supplementation in children, and vitamin A supplementation in vitamin A deficient populations.
\end{abstract}

\section{Introduction}

In the past few years, an inordinate amount of effort has been put in towards the achievement of the millennium development goal (MDG) for child survival- MDG 4. Though some countries are on MDG target to reduce under-five mortality by two-thirds, the total number of child deaths has actually increased in 13 countries [1]. On a more positive note, under-five mortality worldwide has decreased from approximately 9.6 million in 2000 to 7.6 million in 2012 [2]. The death of 19,000 children under age five every day in 2011 [2] is still a major concern, which dictates that evaluations are necessary for further improvement.

Around half of under-five deaths occur in only five countries: India, Nigeria, Democratic Republic of Congo, Pakistan and China [2]. The leading causes of death among children under age five are pneumonia (18\% of all underfive deaths); preterm birth complications (14\%); diarrhea (11\%); intrapartum related complications (complications during birth; 9\%); and malaria (7\%) [2]. Most of these complications are preventable with the correct interventions being implemented. Another major factor leading to the inability to meet proposed reduction in figures of child mortality is the fact that most maternal and child health

\footnotetext{
* Correspondence: zulfiqar.bhutta@aku.edu

Division of Women and Child Health, Aga Khan University, Karachi, Pakistan
}

programs do not reach the world's poorest families [3]. For children who need them the most, survival interventions such as vaccination programs have showed incomplete coverage. Some programs have shown tremendous success, such as the increased coverage of measles vaccination, which have resulted in a $92 \%$ reduction in measles mortality between 2000 and 2008 in sub-Saharan Africa [2]. Problems associated with lack of coverage include poorly designed health care systems in the developing world where a lack of resources including skilled workers are a major concern [3]. In some low and middle income countries (LMICs), such as Pakistan or India, resistance or refusals against vaccines that are deep rooted in social-cultural, religious and political contexts as well as gender-based decision-making in households are direct causes of the high rates of disease burdens such as polio [4].

The aim of this review is to underscore the effectiveness of essential child health interventions that have an alleged impact on reducing child illnesses and improving child survival and can be suitably delivered to resource limited countries.

\section{Methodology}

The methodology has been described in detail elsewhere [4]. In short, the review included all child health interventions based on current World Health Organization (WHO) guidelines and recent Lancet series which have an 
alleged impact on reducing child morbidity and mortality; suitable for delivery in LMICs; and those that can be delivered through the health sector (community level up to the referral level of health care) (Table 1). All relevant childbirth and postnatal intervention reviews were identified from the electronic databases such as the Cochrane database of systematic reviews, the Cochrane database of abstract reviews of effectiveness (DARE), the Cochrane database of systematic reviews of randomized control trials (RCT's), and PubMed. The reference lists of the reviews and recommendations from experts in the field were also used as sources to obtain additional publications. The principal focus was on the existing systematic reviews and meta-analysis. Based on the efficiency of the interventions, these were then classified in categories from $\mathrm{A}$ to $\mathrm{E}$ (where A signified strongly beneficial effect while E indicated harmful effect) on different levels of health sector (community/outreach/referral).

\section{Results}

\section{Promotion of breastfeeding}

Evidence suggests that the safest and most successful way to assure proper growth and development in child is by providing the infant with breast milk from the first hour of birth [5-7]. Exclusive breastfeeding also protects the newborn from various diseases such as respiratory infections and diarrhea, which can lead to insidious outcomes for the newborn. Even though these protective effects of breastfeeding have been stated for years, the duration of exclusive breastfeeding is still far below its optimal level it should be in most countries, both high income countries (HICs) and LMICs. This review assessed the interventions that provided counseling on the benefits of exclusive breastfeeding in the neonatal period and at six months to all pregnant mothers, either individually or in groups.

A review found increased rates of exclusive breastfeeding in neonatal period (risk ratio (RR) 3.06; 95\% confidence interval (CI): $2.10,4.45)$ as well as at 6 months (RR 1.86; 95\% CI: 1.12, 3.09) on comparing individual counseling with routine care [8]. Group counseling, on the other hand, resulted in higher exclusive breastfeeding rates both during neonatal period (RR 3.95; 95\%CI: 2.09, 7.44) and at 6 months (RR 4.49; 95\%CI: 1.90, 10.63) [8]. Other interventions for improving exclusive breastfeeding included providing health education for women of all feeding intentions vs. standard care (RR 1.57; 95\% CI: 1.15, 2.15), peer support for women considering breastfeeding (RR 4.02; $95 \%$ CI: 2.63, 6.14) and breastfeeding promotion packs for women of all feeding intentions (RR 0.93; 95\% CI: 0.80, 1.08) [9].

Similar findings have been reported in a recent review which indicated that educational interventions significantly increased exclusive breastfeeding rates $(\mathrm{EBF})$ rates at day 1 by $43 \%$ (RR $1.43 ; 95 \%$ CI: $1.09,1.87$ ), at $<1$ month by $30 \%$
(RR $1.30 ; 95 \%$ CI: $1.19,1.42)$ and at $1-5$ months by $90 \%$ (RR 1.90; 95\% CI: 1.54, 2.34) [10]. Subgroup analyses showed that individual counseling alone led to a $60 \%$ increase in exclusive breastfeeding rates (RR 1.60; 95\% CI: $1.04,2.48)[10]$.

\section{Promotion and support of continued breastfeeding and complementary feeding}

\section{a) Continued breastfeeding}

Growth faltering is a commonly observed phenomenon in LMICs after about three months of age [11-13]. This growth faltering has traditionally been attributed to three factors: (1) the suggested inadequacy of energy intake from breast milk alone after three or four months; (2) the poor nutritional quality (i.e., low energy and micronutrient content) of the weaning foods commonly introduced in many developing countries; and (3) the adverse effects of infection on energy intake and expenditure. The belief that breast milk alone is nutritionally insufficient after three or four months, combined with the fact that weaning foods given in many LMICS are both nutritionally inadequate and contaminated, led to concern about the socalled 'weanling's dilemma' [14,15]. Because breastfeeding can be lifesaving in LMICs and the health benefits of breastfeeding are widely acknowledged, opinions and recommendations are strongly divided on the optimal duration of exclusive breastfeeding.

A recent Cochrane review [16] found that infants who are exclusively breastfed for six months experience less morbidity from gastrointestinal infection than those who are partially breastfed as of three or four months (RR 0.41 ; 95\% CI: 0.21, 0.78), and no deficits have been demonstrated in growth among infants from either developing or developed countries who are exclusively breastfed for six months or longer. Moreover the results from controlled trials showed that exclusive versus mixed breast-feeding in developing countries resulted in a monthly weight gain from 4-6 months (MD 20.78g/month; 95\% CI: -21.99 , 63.54 ); and from 6-12 months (MD $-2.62 \mathrm{~g} / \mathrm{month}$; $95 \% \mathrm{CI}$ : $-25.85,20.62)$ and a hemoglobin concentration of $<110 \mathrm{~g} /$ dl (RR 1.20; 95\% CI: 0.90, 1.58). The same review using observational studies showed a monthly weight gain from 4-6 months (MD -10.10; 95\% CI: $-27.68,7.48$ ) and from 6-9 months (MD -6.0; 95\% CI: $-54.15,42.15$ ).

\section{b) Education strategies on complementary feeding support}

Period of complementary feeding (CF) (from 6 to 24 months of age) is one of the most critical times for preventing malnutrition [17]. Effect on growth is most evident during this time [11] particularly during the first phase of complementary feeding when foods of low nutrient density begin to replace breast milk and rates of diarrheal illness caused by food contamination are at their highest. This is consistent with results of intervention trials showing that 


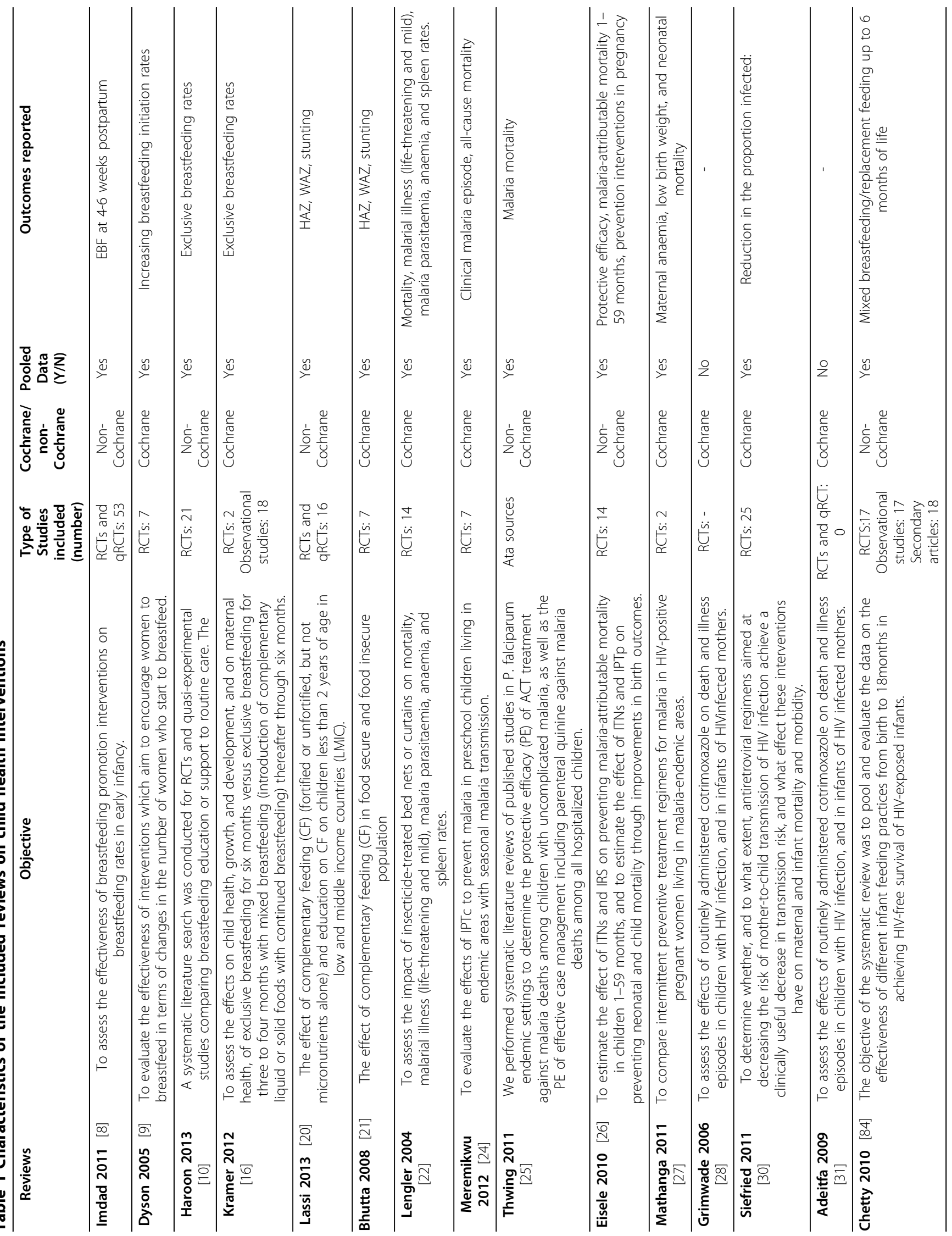




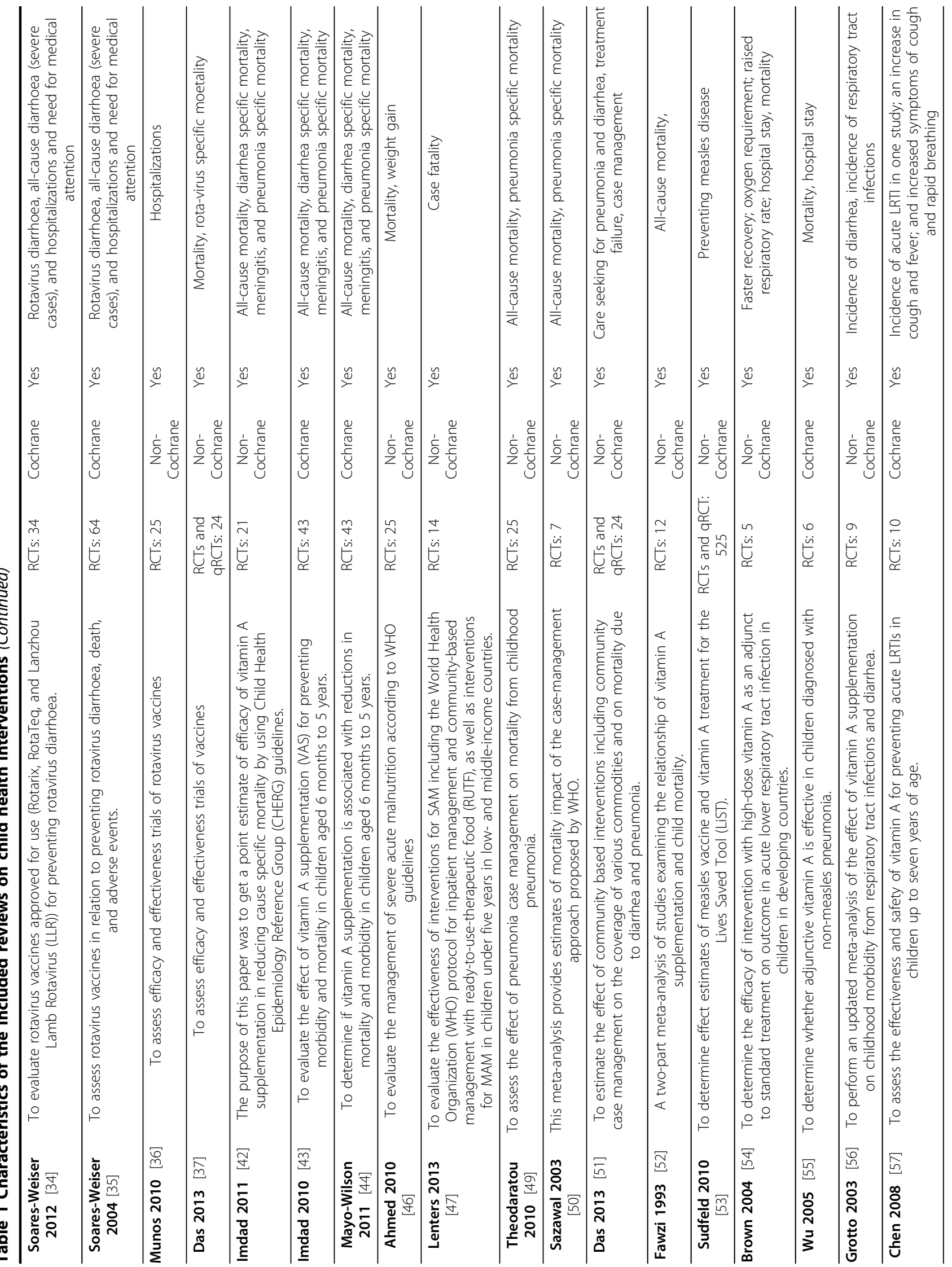


the greatest impact of food supplementation is seen among children less than 2 years of age [18,19]. CF is a food-based intervention, given at the age range of 6-24 months, along with breastfeeding to fulfill the extra needs of the growing infant. Several strategies can be used for promotion of this intervention, such as education about CF as the main treatment, and provision of complementary foods.

A recent review has reported that education on $C F$ alone significantly improved height-for-age Z score (HAZ) (standard mean difference (SMD): 0.23; 95\% CI: 0.09, 0.36), weight-for-age Z score (WAZ) (SMD 0.16, 95\% CI: 0.05, 0.27 ), and significantly reduced the rates of stunting (RR 0.71; 95\% CI: 0.56, 0.91, 5 studies); no significant impact were observed for height and weight gain [20]. However, based on the subgroup analysis; studies from food secure populations indicated education on CF had a significant impact on height gain (SMD 0.35; 95\% CI: 0.08, 0.62), HAZ scores (SMD 0.22; 95\% CI: 0.01, 0.43), and weight gain (SMD 0.40; 95\% CI: 0.02, 0.78), however, stunting reduced non-significantly (RR 0.70; 95\% CI: 0.491 .01 ) [20]. On the other hand, in food insecure population, CF education alone significantly improved HAZ scores (SMD 0.25; 95\% CI: 0.09, 0.42), WAZ scores (SMD 0.26; 95\% CI: $0.12,0.41)$ and significantly reduced the rates of stunting (RR 0.68; 95\% CI: 0.60, 0.76), while CF provision with or without education improved HAZ (SMD 0.39; 95\% CI: $0.05,0.73$ ) and WAZ scores (SMD 0.26; 95\% CI: 0.04, $0.48)$ significantly. Similar results were also reported in an earlier Lancet review [21].

\section{Prevention and management of childhood malaria} a) Provision and promotion of use of insecticide treated nets (ITNs) for children

ITNs not only provide a physical barrier to bites from mosquitoes, but their insecticide component like pyrethroids also repel and kill them.

A Cochrane review reported $17 \%$ protective efficacy (PE) (RR $0.83,95 \%$ CI $0.76,0.90$ ) with ITNs when compared with no nets and 23\% PE compared to untreated nets (RR $0.77,95 \%$ CI $0.63,0.95$ ) and about 5.5 lives (95\% CI 3.39, $7.67)$ can be saved each year for every 1000 children protected with ITNs [22]. It further reported 18\% reduction in all-cause child mortality (RR 0.82; 95\% CI: 0.76, 0.89) [22].

\section{b) Malarial prophylaxis in children:}

Intermittent preventive treatment or intermittent presumptive treatment (IPT) involves giving the drug e.g. sulfadoxine-pyrimethamine, at full therapeutic dose to the whole population at risk at specific times to prevent mortality or morbidity [23].

IPT for malaria in children living in areas with seasonal transmission showed lower rates of clinical malaria during intervention (RR 0.26; 95\% CI: 0.17, 0.38), and during post-intervention (RR 0.98; 95\% CI: 0.82, 1.17) [24]. The same review found lower cases of severe malaria during intervention (RR 0.27; 95\% CI:0.10, 0.76), and lower rates of parasitaemia malaria during intervention (RR 0.35; 95\% CI: $0.25,0.50)$ as well as during post-intervention (RR 1.01; 95\% CI: 0.89, 1.16) [24]. Artemisinin-based combination therapies also showed significant results on reducing malaria in children $1-23$ months of age (RR $0.01 ; 95 \% \mathrm{CI}$ : $0.00,0.06$ ); and children 24-59 months (RR 0.03; 95\% CI: $0.01,0.14)$ [25]. The review also estimated the PE of treatment of severe P. falciparum malaria with effective case management including intravenous quinine on reducing malaria mortality in children 1-59 months to be $82 \%$ (range: 63-94\%) compared to no treatment [25]. Another review estimated 55\%PE with ITNs and indoor-residual spray on reducing malaria-attributable mortality in children 1-59 months (RR 0.45; 95\% CI: 0.39, 0.51) [26].

The use of monthly sulfadoxine-pyrimethamine (SP) compared to a standard 2-dose SP in HIV-positive pregnant women, resulted in non-significant reduction in maternal anemia $(\mathrm{Hb}<11 \mathrm{~g} / \mathrm{dl})(\mathrm{RR} 0.97,95 \% \mathrm{CI0.84}, 1.12)$, however, presence of malaria in the placental blood (placental parasitaemia) decreased (RR 0.42; 95\% CI: 0.23, $0.76)$ [27]. No improvements were observed in in neonatal mortality (RR 0.29; 95\% CI: 0.08, 1.05) [27].

\section{Comprehensive care of children infected or exposed to HIV infection}

HIV infection in children (not on antiretroviral therapy (ART)) follows a more destructive course, with death occurring in about $30 \%$ by the $1^{\text {st }}$ year and $50 \%$ by the age of 2 years [28,29]. Prophylaxis with co-trimoxazole is a drug of choice for infants who are born to HIV infected mothers, since the detection of the HIV from birth till 18 months is very difficult due to the presence of maternal HIV antibodies.

The results of the Cochrane review on administration of cotrimoxazole prophylaxis vs. placebo found a single trial from Zambia and the study reported reduction in child mortality (RR 0.67; 95\% CI: 0.53, 0.85), and hospital admission (RR 0.77; 95\%CI: 0.62, 0.96) [28]. Zidovudine (ZDV) plus lamivudine (3TC) given to mothers from 36 weeks gestation, during labor and for 7 days after delivery and to babies for the first 7 days after birth (PETRA 'regimen A') significantly reduced HIV infection (Efficacy 62.75\%; 95\% CI: 40.76, 84.74) [30].

Iron supplementation may have a role in reducing mortality and morbidity in HIV infected children, but no randomized controlled trials on the subject were found [31].

\section{Promote and provide routine immunization and vaccinations in infants/children}

Expanded Program on Immunization (EPI) schedule for poliomyelitis, diphtheria, pertussis, tetanus, measles and tuberculosis is one of the most cost-effective ways to improve child health [32]. It has been estimated that over 
3 million deaths are averted each year from measles, pertussis and neonatal tetanus by vaccination [33]. Rotaviruses cause viral gastroenteritis and result in more deaths from diarrhea in children under 5 years of age than any other single agent, particularly in LMICs [34]. The WHO recommends that all children should be vaccinated with a monovalent rotavirus vaccine or a pentavalent rotavirus vaccine, with a stronger recommendation for countries where deaths due to diarrhea comprise more than $10 \%$ of all deaths [34]. Immunization against Haemophilus influenzae type $b(\mathrm{Hib})$ is recommended where resources permit its use and the burden of disease is established. WHO considers that pneumococcal conjugate vaccine should be a priority for inclusion in national childhood immunization programs. Countries with mortality among children aged $<5$ years of $>50$ deaths $/ 1000$ births or with more than 50,000 children's deaths annually should make the introduction of PCV-7 a high priority for their immunization programs.

Rotavirus (RV) vaccines were successful in preventing severe rotavirus diarrhea and all-cause diarrhea (severe cases) (RR 0.59; 95\% CI: 0.42, 0.83) [34]. Moreover,RV1 vaccine showed better results compared to RV5- (RR 0.20; 95\% CI: 0.11, 0.35); [34].Efficacy and safety of three main types of rotavirus vaccines (bovine, human, and rhesus) demonstrated results varying from 22 to $89 \%$ to prevent one episode of rotavirus diarrhea, 11 to $44 \%$ to prevent one episode of all-cause diarrhea, and 43 to $90 \%$ to prevent one episode of severe rotavirus diarrhea [35]. Currently marketed rotavirus vaccines can prevent $74 \%$ (95\% CI: $35,90 \%)$ of rotavirus deaths and $47-57 \%$ of rotavirus hospitalizations [36].

A recent review on the effect of oral vaccines in terms of immunogenicity, indicated a greater than two folds rise in the vibriocidal antibody titres (RR 2.24, 95\% CI: $1.32,3.80)$; live oral vaccines showed a more significant rise as compared to killed oral vaccines [37]. A Review by Das et al. reported that cholera vaccinationwas associated with a $52 \%$ reduction in cholera incidence (RR 0.48, 95\% CI: $0.35,0.64)$ while, shigella vaccine had no impact on reducing the incidence of the disease (RR: 0.72, 95\% CI: $0.37,1.39)$ [37].

\section{Vitamin A supplementation from 6 months of age in Vitamin A deficient population}

Vitamin A is a term used for a group of fat-soluble compounds required for the growth and differentiation of different body cells [38]. It also acts as an anti-oxidant agent and is especially involved in regeneration of epithelium of respiratory and gastrointestinal tracts [39]. Deficiency of vitamin A makes infant and children susceptible to infections [40]. Intervention with vitamin A in neonatal period and in children older than six months of age has shown reduction in all-cause mortality and cause specific mortality of diarrhea and measles [21,41].

Recent Cochrane and non-Cochrane reviews reported significant impact of vitamin A supplementation in reducing mortality due to any unspecified cause (RR 0.75; 95\% CI: 0.65-0.87) [42]; (RR 0.76; 95\% CI: 0.69-0.83) [43]; (RR 0.76 ; 95\% CI: $0.69-0.83$ ) [44] as well as mortality due to diarrhea: (RR 0.68; 95 \% CI: 0.57-0.81) [42], (RR 0.72; 95\% CI: 0.57-0.91) [43], (RR 0.72; 95\% CI: 0.57-0.91) [44]. The reviews did not find any impact of vitamin A supplementation on mortality due to pneumonia, however mortality due to measles decreased (RR 0.50; 95\% CI: 0.37-0.67) [43]. The review by Mayo-Welson et al. 2011 also reported reduced incidence of diarrhea: (RR 0.85; 95\% CI: $0.82-$ 0.87 ), vision problems (RR 0.32; 95\% CI: 0.21-0.50), and xerophthalmia (RR 0.31; 95\% CI: 0.22-0.45) [44] with supplementation.

\section{Management of severe acute malnutrition}

Severe acute malnutrition (SAM) in children is defined as having a weight-for-height $\mathrm{Z}$ score of $<3$ according to WHO growth standards; visible wasting; or the presence of nutritional edema. It is estimated that malnutrition directly or indirectly is responsible for $35 \%$ of deaths occurring in children under five, so it is vital to correct malnutrition globally in order to decrease child mortality [45].

Implementation of the WHO guidelines (that includes early initiation of fluids, proper feeding, slow oral rehydration, broad-spectrum antimicrobial therapy and promptly managing all complications if present) showed reduction in mortality (RR 0.39; 95\%CI: 0.28, 0.53) when compared with no guidelines. On the other hand, ready to use therapeutic food RUTF (a dry, solid diet without any addition of water so risk of bacterial contamination is eliminated) showed improvement in weight gain $(\mathrm{g} / \mathrm{kg} /$ day) (Mean Difference (MD) 1.36; 95\% CI: 0.33, 2.40) when compared with provision of corn flour in moderately malnourished children [46]. A recent review reported a reduction (ranged $3.4 \%$ to $35 \%$ ) in case fatality rates among children who were treated in in-patient using the WHO protocol [47]. For community-based treatment of SAM, children given RUTF were $51 \%$ more likely to achieve nutritional recovery than the standard care group (RR 1.51; 95\% CI: 1.04, 2.20) [47].

\section{Case management of childhood pneumonia}

About 7.6 million children die every year before they reach their fifth birthday [48]. The main causes of these deaths are: acute respiratory infections, diarrhea, measles, malaria, malnutrition, or often a combination of these conditions. WHO and UNICEF launched a strategy, called Integrated Management of Childhood Illness (IMCI), to reduce deaths due to these manageable 
and preventable causes. IMCI is a strategy to reduce childhood mortality and morbidity from acute respiratory infections, diarrhea, measles, malaria, and malnutrition.

Systematic analysis by Theodoratou et al. 2010 found a significant impact of community case management with antibiotic on reducing ARI mortality (RR: $0.65 ; 95 \% \mathrm{CI}$ : $0.52,0.82$ ) and all-cause mortality (RR: $0.79 ; 95 \%$ CI: 0.70 , 0.88 ) among children $0-5$ years [49]. A relatively older review also reported similar findings on reducing total mortality (RR 0.76; 95\% CI: $0.67,0.86$ ) and pneumonia mortality (RR 0.64; 95\% CI: $0.51,0.80$ ) among children $0-4$ years of age [50]. However, a recent pooled analysis of community based interventions found a significant increase in care seeking (13\%) and a signficant decrease in treatment failure rates (40\%) for pneumonia [51]. The review also reported beneficial impact of community case management of pneumonia on reducing pneumonia specific mortality by $32 \%$ [51].

Among children with measles, vitamin A supplementation had a protective effect on reducing mortality (odds ratio (OR 0.39; 95\% CI: 0.22, 0.66) [52]. Another review reported that a single dose of measles vaccine can reduce the incidence ofmeasles disease by $85 \%$ [95\% CI: 83, 87) [53]. The stratified data from the same review showed that among children who were provided with vitamin A (two doses of 200,000 IU for children $>1$ year and 100,000 IU for infants), measles mortality significantly reduced by $62 \%$ (RR 0.38; 95\% CI: 0.18,0.81) [53].

Vitamin A as part of treatment for non-measles associated pneumonia for children above 6 months showed thatwhen a high-dose of vitamin A was given along with standard treatment of acute lower respiratory tract infection, no significant recovery was seen in children in developing countries aged from 1 month to 6 years [54]. Other reviews showed no significant reduction in mortality associated with pneumonia in children treated with vitamin A compared to those who were not (OR 1.29; $95 \%$ CI: $0.63,2.66)$. Also, there was no significant difference in duration of hospital stay, and disease severity after supplementary high-dose vitamin A was significantly worse compared with placebo [55].

Grotto et al, on the other hand, indicated that vitamin A supplementation has no consistent overall protective effect on the incidence of diarrhea (RR 1.00; 95\% CI: 0.94, 1.07) and that it slightly increases the incidence of respiratory tract infections (RR 1.08; 95\% CI: 1.05, 1.11) [56]. Similarly, Chen et al. reported that most of the included studies found no significant effect of vitamin A on the incidence of acute LRTI, or prevalence of symptoms of acute LRTI [57]. Lamberti et al. indicated that pneumonia mortality was higher among infants who were not breastfed compared to exclusively breastfed infants of 0-5 months of age (RR 14.97; 95\% CI: $0.67,332.74)$ and among not breastfed compared to breastfed infants and young children 6-23 months of age (RR 1.92; 95\% CI: 0.79, 4.68) [58].

\section{Case management of diarrhea}

\section{a. Preventive zinc supplementation in children}

A number of intervention trials have been conducted in a variety of settings to assess the impact of preventive zinc supplementation on children's health and development. The results of these studies are inconsistent, possibly because of differences in the underlying zinc status or other characteristics of the study populations or discrepancies in the research methods $[59,60]$. Previous reviews have shown that preventive zinc supplementation has a beneficial effect on reduction of incidence of diarrhea, pneumonia and other infectious diseases [61].

Zinc supplementation in children with diarrhea showed a decrease in diarrhea specific mortality (RR $0.81 ; 95 \% \mathrm{CI}$ : $0.64,1.03$ ), in pneumonia specific mortality (RR 0.86; $95 \%$ CI: $0.66,1.12)$ and similar reductions in diarrhea and pneumonia specific morbidities [62].

\section{b. Therapeutic zinc supplementation in children}

Zinc deficiency is one of the leading risk factors for morbidity and mortality $[63,64]$. It is estimated that zinc deficiency is responsible for approximately 800,000 excess deaths annually among children under 5 years of age. The existing literature provides evidence of a beneficial effect of therapeutic zinc supplementation for the treatment of diarrhea shown to decrease the duration and severity of the diarrheal episode, diarrhea hospitalization rates and, in some studies, all-cause mortality [65].

Zinc supplementation may shorten the duration of diarrhea by around 10 hours (MD - 10.44 hours; 95\% CI: -21.13 to 0.25$)$. It also reduces the number of children whose diarrhea persists until day seven (RR 0.73; 95\% CI: 0.61 to 0.88 ), and the duration of persistent diarrhea shortens by around 16 hours (MD -15.84 hours; 95\% CI: -25.43 to -6.24$)$ [66].

\section{c. ORS for diarrhea in children}

Children who lose a large volume of liquid stool may develop moderate or severe dehydration; in the most severe cases this can lead to death. These children should be given rehydration therapy in order to restore the lost fluids and electrolytes. Oral rehydration solutions (ORS) have had a massive impact worldwide in reducing the number of deaths related to diarrhea. Most ORS is in the form of a sugar-salt solution, but over the years people have tried adding a variety of compounds ('glucose polymers') such as whole rice, wheat, sorghum, and maize.

A review by Gregorio et al showed decreased unscheduled IV infusions (RR 0.75; 95\% CI: 0.59-0.95) with polymer based ORS compared to glucose based ORS [67]. Hartling et al., on the other hand compared ORS therapy with intravenous therapy and reported significant risk 
difference intreatment failure (RD 4\%; 95\% CI: 1\%, 7\%); and non-significant impact on hospital stay (WMD -1.2; $95 \%$ CI: $-2.38,0.02)$. The same review reported 50 number needed to treat (NNT) forphelibitis: (95\% CI: 25-100); and 33 for paralytic illeus(95\% CI: 20, 100) [68]. When reduced osmolarity ORS was compared with WHO standard ORS, a reduction in unscheduled IV Infusion was observed (OR 0.59; 95\% CI: 0.45, 0.79) [69].

Lenters et al. reported that the co-promotion of zinc and ORS indicated that mothers were 1.82 (95\% CI 1.17, 2.85) times more likely to treat their child's diarrhoea episode than mothers in the comparison group [70]. Mothers who were exposed to media and social marketing strategies through radio, television and cinema spots as well as community outreach activities and print materials were 2.05 $(95 \%$ CI $0.78,5.42)$ times more likely to use ORS to treat their child's diarrhoea episode than mothers who were not exposed [70].

Vomiting due to acute gastroenteritis limits the success of oral rehydration leading to an increased use of intravenous rehydration, need for prolonged emergency department stays and hospitalizations. Das et al. reported that use of antiemetic in diarrhoea was associated with a significant $54 \%$ reduction in the incidence of vomiting (RR 0.46 ; 95\% CI: $0.35,0.61)$ and $54 \%$ reduction in the incidence of hospitalization (RR: 0.46, 95\% CI: 0.29, 0.74) [71].

\section{d. Treatment of dysentery in children}

Shigellosis occurs predominantly in LMICs and is most common where overcrowding and poor sanitation exist. Shigellosis is a bacterial infection of the colon that causes diarrhea and can lead to death. Dysentery is frequent mucoid or bloody stools. When dysentery is caused by Shigella it is called Shigella dysentery. The intention of giving antibiotics in shigellosis is to speed recovery, reduce the seriousness of the disease, and reduce the length of time patients are infective. However, some antibiotics can have serious side effects while others may not be effective against the Shigella bacteria.

Reduced episodes of diarrhoea at follow-up were seen with Furazolidone versus no drug (RR 0.21; 95\% CI: 0.09, 0.48 ) as well as with cotrimoxazole versus no drug (RR 0.30; 95\% CI: 0.15, 0.59) [72]. However, treatment with one of the three WHO-recommended antibiotics (ciprofloxacin, ceftriaxone and pivmecillinam) resulted in a clinical failure rate of $0.1 \%$ (95\% CI: $-0.2,0.5 \%)$ [73]. On the other hand, when two different antibiotics (Pivmecillinam and Ciprofloxacin) were used it resulted in $82 \%$ reduction in clinical failure (RR 0.18; 95\% CI: 0.10, 0.33). While Pivmecillinam, Ciprofloxacin and Ceftriaxone reported 96\% reduction in bacteriological failure of (RR 0.04; 95\% CI: $0.01,0.12)$ [74].

\section{f. Treatment of cholera in children}

Cholera is caused by ingesting food or water containing the bacterium Vibrio cholera. The disease can spread rapidly among populations lacking access to safe water and adequate sanitation facilities. Symptoms of cholera include acute watery diarrhea, vomiting, and severe dehydration, which can lead to death within 24 hours if left untreated [75]. Because cholera is associated with significant electrolyte loss especially among children, the use of ORS with reduced sodium levels may place patients at a greater risk for developing biochemical hyponatremia (low blood sodium levels $<130 \mathrm{mmol} / \mathrm{L}$ ) [76], which can result in severe illness including seizures, respiratory arrest, coma (symptomatic hyponatremia), and even death.

For glucose-based ORS, biochemical hyponatraemia (blood sodium levels $<130 \mathrm{mmol} / \mathrm{L}$ ) was more common with ORS $\leq 270$ (RR 1.67, 95\% CI 1.09, 2.57), while a higher level of severe biochemical hyponatraemia (blood sodium levels $<125 \mathrm{mmol} / \mathrm{L}$ ) in the same group was not significant (RR 1.58, 95\% CI 0.62, 0.04). In the ORS $\leq 270$ group (rice base ORS), duration of diarrhoea was shorter (MD -11.42 hours, 95\% CI -13.80, -9.04) [77]. The antibiotic treatment of cholera showed $63 \%$ reduction in clinical failure (RR 0.37; 95\% CI: 0.19, 0.71) [74].

\section{Discussion}

The threat to child survival continues to be of grave concern. Therefore, this paper summarizes all the essential preventive and therapeutic child health interventions for preventing illnesses and improving child survival. The importance of these interventions have been addressed in previous publications [78-82] and more recently in the Lancet Neonatal Series [83]. However this review progresses further by collating and analyzing existing evidence to assist health professionals and policy makers reduce the current burden of child morbidity and mortality.

What cannot be stressed enough is the importance of exclusive breastfeeding of children till at least the age of 6 months; this ensures proper growth and development of the child. To prevent growth faltering or a decline in the child's motor and physical development, continued breastfeeding is an intervention that is being implemented in many regions where mothers may be substituting poor quality weaning foods in place of breastfeeding. It should also be noted that poverty and poor water and sanitary conditions are some of the underlying causes of poor child growth and development and infection- specific mortality; and that, breastfeeding, alone, cannot contribute in improving health and survival. Therefore, promotion of breastfeeding should be implemented in conjunction with a larger strategy that includes promotion of complementary feeding, improved water and sanitation, and better health care services.

Interventions to target the main causes of under-five mortality including pneumonia, diarrhea, malaria and under nutrition is the key to further success in bringing 
down child mortality. Interventions including antibiotics, ITNs, and improved family care need to be implemented to further reduce child morbidity and mortality rates. In endemic regions or tropical areas, malarial prophylaxis is vital; the expanded program on immunization (EPI) has been and will continue to be one of the most cost effective methods of improving mortality and morbidity rates. Evidence suggested that ITN use can reduce child mortality by $18 \%$ and 5.5 lives can be saved annually for every 1000 children between 1-59 months protected. In areas with seasonal transmission, IPT showed a dramatic decrease in clinical malaria during intervention, as well as rates of parasitemia post intervention. However, long-term followup studies are needed for efficacy of IPT use in children, including its safety.

Preventive zinc supplementation shows promising benefits in reducing diarrhea specific mortality but further supporting data is required. On the other hand, therapeutic zinc supplementation has a beneficial effect on reducing duration and severity of acute and persistent diarrhea. The results indicate that scaling up the use of zinc in health systems is feasible particularly in LMICs. However, the evidence for beneficial effect of zinc in the treatment of pneumonia, malaria and tuberculosis is limited and needs further evaluation. There are a number of available opportunities to deliver zinc supplementation as one component of programs to prevent micronutrient deficiencies and to address other nutrition and health needs of infants and children. Efforts are needed to test these delivery mechanisms and evaluate their potential for providing cost-effective preventive zinc supplementation to high-risk target groups on a large scale.

Multi-country evaluation of implication of IMCI has shown that it has been very effective in reducing the mortality and morbidity from ARI, diarrhea, measles and malnutrition. It is cost effective and applicable on larger scale. Considering the strengths of the IMCI strategy and the existing commitments and investments by countries, the IMCI strategy, should be continued and expanded, as part of a broader investment approach to improve child health outcomes. Vitamin A supplementation in children after six months of age reduces all-cause mortality and diarrhea specific and measles specific mortality. There is a very limited evidence for protective effect of vitamin A for prevention of pneumonia specific mortality and morbidity. Due to its beneficial effect on all-cause and diarrhea-specific mortality, routine vitamin A supplementation in this age group is recommended.

As we move closer to the deadline for the target of the MDGs, a closer look at the existing programs and interventions was necessary to evaluate where opportunities for improvement lie. This paper is a comprehensive and thorough summary of essential child health interventions and can be used by health professionals and decision makers from the field. The strength of this paper lies in the fact that it includes and summarizes evidence from all recent Cochrane and non-Cochrane reviews on child health interventions. However, at times the quality of all included studies within the review could not be ensured which limits the quality of the data obtained.

\section{Conclusion}

High rates of child mortality are unquestionably linked to inadequate and poor quality health services available in the early years of life both to mother and child. In a majority of countries, especially low-income countries, the availability of health care services, vaccination programs and other vital amenities are inadequate, of poor quality, and require positive transformation. Because a major proportion of child deaths occur in LMICs, the need for appropriate education and awareness is vital prior to establishing interventions. Empowerment of women, removing barriers to accessibility to health care services, increased education and awareness in communities, and shifting the focus to evidence based interventions may help inculcate healthy practices among mothers and improve child survival rates. Appropriate culturally sensitive education and awareness provided to the communities, followed by timely implementation of discussed interventions which can be infused with existing healthcare practices, will definitely bring the required improvement in child health and survival.

\section{Peer review}

The reviewer reports for this article can be found in Additional File 1.

\section{Additional material}

Additional file 1: Peer review reports are included in additional file 1

\section{Competing interests}

We do not have any financial or non-financial competing interests for this review.

\section{Acknowledgements}

The publication of these papers and supplement was supported by an unrestricted grant from The Partnership for Maternal, Newborn and Child Health

\section{Declarations}

This article has been published as part of Reproductive Health Volume 11 Supplement 1, 2014: Essential intervention for maternal, newborn and child health. The full contents of the supplement are available online at www. reproductive-health-journal.com/supplements/11/S1. Publication charges for this collection were funded by the Partnership for Maternal, Newborn \& Child Health (PMNCH).

Published: 21 August 2014 


\section{References}

1. United Nations Children's Fund: Levels and trends in child mortality 2012: Estimates developed by the UN Inter-agency Group for Child Morality Estimation. UNICEF, WHO, The World Bank and UN population division 2012.

2. Danzhen Y, Jin RN, Tessa W: Levels and Trends in Child Mortality. 2012 [www.who.int/entity/maternal_child_adolescent/documents/ levels_trends_child_mortality_2012.pdf].

3. WHO: Trends in maternal mortality: 1990 to 2010. WHO, UNICEF, UNFPA and The World Bank estimates. Geneva, Switzerland. 2012.

4. Lassi ZS, Salam RA, Dai JK, Bhutta ZA: Essential interventions for maternal, newborn and child health: background and methodology. Reproductive Health 2014, 11(Suppl 1):S1.

5. Chung M, Raman G, Trikalinos T, Lau J, Ip S: Interventions in primary care to promote breastfeeding: an evidence review for the US Preventive Services Task Force. Ann Intern Med 2008, 149(8):565-582.

6. Gartner LM, Morton J, Lawrence RA, Naylor AJ, O'Hare D, Schanler RJ, Eidelman Al: Breastfeeding and the use of human milk. Pediatrics 2005, 115(2):496-506.

7. Morrow AL, Guerrero ML, Shults J, Calva JJ, Lutter C, Bravo J, RuizPalacios G, Morrow RC, Butterfoss FD: Efficacy of home-based peer counselling to promote exclusive breastfeeding: a randomised controlled trial. Lancet 1999, 353(9160):1226-1231.

8. Imdad A, Yakoob MY, Bhutta Z: Effect of breastfeeding promotion interventions on breastfeeding rates, with special focus on developing countries. BMC Public Health 2011, 11(Suppl 3):S24.

9. Dyson L, McCormick F, Renfrew M: Interventions for promoting the initiation of breastfeeding. Cochrane Database Syst Rev 2005, 2(2): CD001688

10. Haroon S, Das JK, Salam RA, Imdad A, Bhutta ZA: Breastfeeding promotion interventions and breastfeeding practices: a systematic review. BMC Public Health 2013, 13(3):1-18.

11. Shrimpton R, Victora CG, de Onis M, Costa Lima R, Blossner M, Clugston G Worldwide timing of growth faltering: implications for nutritional interventions. Pediatr 2001, 107(5):e75-e75.

12. Waterlow JC, Thomson AM: Observations on the adequacy of breastfeeding. Lancet 1979, 314(8136):238-242.

13. Whitehead RG, Paul AA: Growth charts and the assessment of infant feeding practices in the western world and in developing countries. Early Hum Dev 1984, 9(3):187-207.

14. Rowland MGM, Barrell RAE, Whitehead RG: Bacterial contamination in traditional Gambian weaning foods. Lancet 1978, 311(8056):136-138.

15. Rowland MG: The weanling's dilemma: are we making progress? Acta Paediatr 1986, 75(s323):33-42.

16. Kramer MS, Kakuma R: Optimal duration of exclusive breastfeeding. Cochrane Database Sys Rev 2012, 8(8):CD003517.

17. World Bank: World Bank Repositioning Nutrition as Central to Development:A Strategy for Large Scale Action. The World Bank Washington, DC; 2005

18. Lutter CK, Mora JO, Habicht J-P, Rasmussen KM, Robson DS, Herrera MG: Age-specific responsiveness of weight and length to nutritional supplementation. Am J Clin Nutr 1990, 51(3):359-364.

19. Schroeder DG, Pachon $H$, Dearden KA, Ha TT, Lang TT, Marsh DR: An integrated child nutrition intervention improved growth of younger, more malnourished children in northern Viet Nam. Food Nutr Bull 2002, 23(Supplement 2):50-58

20. Lassi ZS, Das JK, Zahid G, Imdad A, Bhutta ZA: Impact of education and provision of complementary feeding on growth and morbidity in children less than 2 years of age in developing countries: a systematic review. BMC Public Health 2013, 13(Suppl 3):S13.

21. Bhutta ZA, Ahmed T, Black RE, Cousens S, Dewey K, Giugliani E, Haider BA Kirkwood B, Morris SS, Sachdev HPS, et al: What works? Interventions for maternal and child undernutrition and survival. Lancet 2008, 371(9610):417-440.

22. Lengeler $C$ : Insecticide-treated bed nets and curtains for preventing malaria. Cochrane Database Syst Rev 2004, 2(2):CD000363.

23. Greenwood B: Intermittent preventive treatment-a new approach to the prevention of malaria in children in areas with seasonal malaria transmission. Trop Med Int Health 2006, 11(7):983-991.

24. Meremikwu MM, Donegan S, Sinclair D, Esu E, Oringanje C: Intermittent preventive treatment for malaria in children living in areas with seasonal transmission. Cochrane Database Syst Rev 2012, 2(2):CD003756.
25. Thwing J, Eisele TP, Steketee RW: Protective efficacy of malaria case management and intermittent preventive treatment for preventing malaria mortality in children: a systematic review for the Lives Saved Tool. BMC Public Health 2011, 11(3):1-9.

26. Eisele TP, Larsen D, Steketee RW: Protective efficacy of interventions for preventing malaria mortality in children in Plasmodium falciparum endemic areas. Int J Epidemiol 2010, 39(suppl 1):i88-i101.

27. Mathanga DP, Uthman OA, Chinkhumba J: Intermittent preventive treatment regimens for malaria in HIVâ€ Âpositive pregnant women. Cochrane Database Syst Rev 2011, 9(9):CD006689.

28. Grimwade K, Swingler GH: Cotrimoxazole prophylaxis for opportunistic infections in children with HIV infection. Cochrane Database Syst Rev 2006, 1(1):CD003508

29. Newell M-L, Coovadia H, Cortina-Borja M, Rollins N, Gaillard P, Dabis F: Mortality of infected and uninfected infants born to HIV-infected mothers in Africa: a pooled analysis. Lancet 2004, 364(9441):1236-1243.

30. Siegfried $N$, van der Merwe $L$, Brocklehurst $P$, Sint $\Pi T$ : Antiretrovirals for reducing the risk of mother-to-child transmission of HIV infection. Cochrane Database Syst Rev 2011, 7(7):CD003510.

31. Adetifa I, Okomo U: Iron supplementation for reducing morbidity and mortality in children with HIV. Cochrane Database Syst Rev 2009, 1(1): CD006736.

32. The World Bank: World Development Report 1993: investing in health Oxford: Oxford University Press; 1993.

33. Cutts FT: Advances and challenges for the expanded programme on immunization. Br Med Bull 1998, 54(2):445-461.

34. Soares-Weiser K, MacLehose H, Bergman H, Ben-Aharon I, Nagpal S, Goldberg E, Pitan F, Cunliffe N: Vaccines for preventing rotavirus diarrhoea: vaccines in use. Cochrane Database Syst Rev 2012, 11(11):CD008521.

35. Soares-Weiser K, Goldberg E, Tamimi G, Pitan OC, Leibovici L: Rotavirus vaccine for preventing diarrhoea. Cochrane Database Syst Rev 2004, 1(1) CD002848

36. Munos MK, Walker CLF, Black RE: The effect of rotavirus vaccine on diarrhoea mortality. Int J Epidemiol 2010, 39(suppl 1):i56-i62.

37. Das JK, Tripathi A, Ali A, Hassan A, Dojosoeandy C, Bhutta ZA: Vaccines for the prevention of diarrhea due to cholera, shigella, ETEC and rotavirus. BMC Public Health 2013, 13(Suppl 3):S11.

38. Bates C: Vitamin A. Lancet 1995, 345(8941):31-35.

39. Mecocci P, Polidori MC, Troiano L, Cherubini A, Cecchetti R, Pini G, Straatman M, Monti D, Stahl W, Sies H: Plasma antioxidants and longevity: a study on healthy centenarians. Free Radic Biol Med 2000, 28(8):1243-1248

40. Green HN, Mellanby E: Vitamin A as an anti-infective agent. BMJ 1928, 2(3537):691

41. Glasziou PP, Mackerras DE: Vitamin A supplementation in infectious diseases: a meta-analysis. BMJ 1993, 306(6874):366.

42. Imdad A, Yakoob MY, Sudfeld C, Haider B, Black R, Bhutta Z: Impact of vitamin A supplementation on infant and childhood mortality. BMC Public Health 2011, 11(Suppl 3):S20

43. Imdad A, Herzer K, Mayo-Wilson E, Yakoob MY, Bhutta ZA: Vitamin A supplementation for preventing morbidity and mortality in children from 6 months to 5 years of age. Cochrane Database Syst Rev 2010, 12(12):CD008524.

44. Mayo-Wilson E, Imdad A, Herzer K, Yakoob MY, Bhutta ZA: Vitamin A supplements for preventing mortality, illness, and blindness in children aged under 5: systematic review and meta-analysis. BMJ 2011, 343.

45. WHO: Severe Acute Malnutrition. [http://www.who.int/nutrition/topics/ malnutrition/en/index.html].

46. Ahmed T, Ahmed S, Mahfuz M, Abdullah K, Cravioto A, Sack D: Systematic review of management of childhood severe malnutrition. Chapter 7. Nutrition intervention for maternal and child health and survival. 2010.

47. Lenters LM, Wazny K, Webb P, Ahmed T, Bhutta ZA: Treatment of severe and moderate acute malnutrition in low-and middle-income settings: a systematic review, meta-analysis and Delphi process. BMC Public Health 2013, 13(Suppl 3):S23.

48. Liu L, Johnson HL, Cousens S, Perin J, Scott S, Lawn JE, Rudan I, Campbell H, Cibulskis R, Li M: Global, regional, and national causes of child mortality: an updated systematic analysis for 2010 with time trends since 2000. Lancet 2012, 379(9832):2151-2161.

49. Theodoratou E, Al-Jilaihawi S, Woodward F, Ferguson J, Jhass A, Balliet M, Kolcic I, Sadruddin S, Duke T, Rudan I: The effect of case management on 
childhood pneumonia mortality in developing countries. Int I Epidemiol 2010, 39(suppl 1):i155-1171.

50. Sazawal S, Black RE: Effect of pneumonia case management on mortality in neonates, infants, and preschool children: a meta-analysis of community-based trials. Lancet Infect Dis 2003, 3(9):547-556.

51. Das JK, Lassi ZS, Salam RA, Bhutta ZA: Effect of community based interventions on childhood diarrhea and pneumonia: uptake of treatment modalities and impact on mortality. BMC Public Health 2013, 13(Suppl 3):S29.

52. Fawzi WW, Chalmers TC, Herrera MG, Mosteller F: Vitamin A supplementation and child mortality. JAMA 1993, 269(7):898-903.

53. Sudfeld CR, Navar AM, Halsey NA: Effectiveness of measles vaccination and vitamin A treatment. Int J Epidemiol 2010, 39(suppl 1):i48-i55.

54. Brown N, Roberts C: Vitamin A for acute respiratory infection in developing countries: a meta-analysis. Acta Paediatr 2004, 93(11):1437-1442.

55. Wu T, Ni J, Wei J: Vitamin A for non-measles pneumonia in children. Cochrane Database Syst Rev 2005, 3(3):CD003700.

56. Grotto I, Mimouni M, Gdalevich M, Mimouni D: Vitamin A supplementation and childhood morbidity from diarrhea and respiratory infections: a meta-analysis. J Pediatr 2003, 142(3):297-304.

57. Chen H, Zhuo Q, Yuan W, Wang J, Wu T: Vitamin A for preventing acute lower respiratory tract infections in children up to seven years of age. Cochrane Database Syst Rev 2008, 1(1):CD006090.

58. Lamberti LM, Zakarija-GrkoviÄキ I, Walker CLF, Theodoratou E, Nair H, Campbell H, Black RE: Breastfeeding for reducing the risk of pneumonia morbidity and mortality in children under two: a systematic literature review and meta-analysis. BMC Public Health 2013, 13(3):1-8.

59. Bates CJ, Evans PH, Dardenne M, Prentice A, Lunn PG, Northrop-Clewes CA, Hoare S, Cole TJ, Horan SJ, Longman SC: A trial of zinc suplementation in young rural Gambian children. Br J Nutr 1993, 69(1):243-255.

60. Richard SA, Zavaleta N, Caulfield LE, Black RE, Witzig RS, Shankar AH: Zinc and iron supplementation and malaria, diarrhea, and respiratory infections in children in the Peruvian Amazon. Am J Trop Med Hyg 2006, 75(1):126-132.

61. Brown KH, Peerson JM, Baker SK, Hess SY: Preventive zinc supplementation among infants, preschoolers, and older prepubertal children. Food Nutr Bull 2009, 30(Supplement 1):12S-40S.

62. Yakoob MY, Theodoratou E, Jabeen A, Imdad A, Eisele TP, Ferguson J, Jhass A, Rudan I, Campbell H, Black RE: Preventive zinc supplementation in developing countries: impact on mortality and morbidity due to diarrhea, pneumonia and malaria. BMC Public Health 2011, 11(Suppl 3):S23.

63. Davidsson L, Fontaine O, Hotz C: Conclusions of the joint WHO/UNICEF/ IAEA/IZiNCG interagency meeting on zinc status indicators. Food Nutr Bull 2007, 28(3).

64. King JC, Turnlund JR: Human zinc requirements. Zinc in human biology Springer; 1989, 335-350.

65. Walker CLF, Black RE: Zinc for the treatment of diarrhoea: effect on diarrhoea morbidity, mortality and incidence of future episodes. Int $\mathrm{J}$ Epidemiol 2010, 39(suppl 1):i63-i69.

66. Lazzerini M, Ronfani L: Oral zinc for treating diarrhoea in children. Cochrane Database Syst Rev 2013, 1(1):CD005436.

67. Gregorio GV, Gonzales ML, Dans LF, Martinez EG: Polymer-based oral rehydration solution for treating acute watery diarrhoea. Cochrane Database Syst Rev 2009, 2(2):CD006519.

68. Hartling L, Bellemare S, Wiebe N, Russell K, Klassen TP, Craig W: Oral versus intravenous rehydration for treating dehydration due to gastroenteritis in children. Cochrane Database Syst Rev 2006, 3(3):CD004390.

69. Hahn S, Kim S, Garner P: Reduced osmolarity oral rehydration solution for treating dehydration caused by acute diarrhoea in children. Cochrane Database Syst Rev 2002, 1(1):CD002847.

70. Lenters LM, Das JK, Bhutta ZA: Systematic review of strategies to increase use of oral rehydration solution at the household level. BMC Public Health 2013, 13(Suppl 3):S28.

71. Das JK, Kumar R, Salam RA, Freedman S, Bhutta ZA: The effect of antiemetics in childhood gastroenteritis. BMC Public Health 2013, 13(Suppl 3):S9.

72. Christopher PR, David KV, John SM, Sankarapandian V: Antibiotic therapy for Shigella dysentery. Cochrane Database Syst Rev 2010, 8(8):CD006784.

73. Traa BS, Walker CLF, Munos M, Black RE: Antibiotics for the treatment of dysentery in children. Int J Epidemiol 2010, 39(suppl 1):i70-i74.
74. Das JK, Ali A, Salam RA, Bhutta ZA: Antibiotics for the treatment of Cholera, Shigella and Cryptosporidium in children. BMC Public Health 2013, 13(Suppl 3):S10.

75. Sack DA, Sack RB, Nair GB, Siddique AK: Cholera. Lancet 2004, 363(9404):223-233

76. Fuchs GJ: A better oral rehydration solution?: An important step, but not a leap forward. BMJ 2001, 323(7304):59.

77. Musekiwa A, Volmink J: Oral rehydration salt solution for treating cholera: $\leq 270 \mathrm{mOsm} / \mathrm{L}$ solutions vs $\geq 310 \mathrm{mOsm} / \mathrm{L}$ solutions. Cochrane Database Syst Rev 2011, 12(12):CD003754.

78. Bhutta ZA, Das JK, Walker N, Rizvi A, Campbell H, Rudan I, Black RE, Lancet Diarrhoea and Pneumonia Interventions Study Group: Interventions to address deaths from childhood pneumonia and diarrhoea equitably: what works and at what cost? Lancet 2013, 381(9875):1417-1429.

79. Bhutta ZA, Das JK, Rizvi A, Gaffey MF, Walker N, Horton S, Webb P, Lartey A, Black RE, Lancet Nutrition Interventions Review Group, Maternal and Child Nutrition Study Group: Evidence-based interventions for improvement of maternal and child nutrition: what can be done and at what cost? Lancet 2013, 382(9890):452-477.

80. WHO: WHO Guidelines on HIV and infant feeding 2010. An updated Framework for Priority action Available at: [http://www.unicef.org/ nutrition/files/HIV_Inf_feeding_Framework_2012.pdf]. World Health Organization; 2012, [accessed on March 3, 2014].

81. WHO: Integrated management of childhood illnesses Available at: [http://whqlibdoc.who.int/publications/2008/9789241597289_eng.pdf]. Department of child and adolescent health and development WHO and UNICEF; 2008, [accessed on March 3, 2014].

82. WHO.: Pocket book for Hospital care for children: guidelines for the management of common illnesses with limited resources. Available at: [http://whqlibdoc.who.int/publications/2005/9241546700.pdf]. Geneva, Switzerland. : World Health Organization; 2005, \{accessed on March 3, 2014).

83. Bhutta ZA, Das JK, Bahl R, Lawn JE, Salam RA, Paul VK, Sankar JM, Blencowe H, Rizvi A, Chou VB, et al: Can available interventions end preventable deaths in mothers, newborn babies, and stillbirths, and at what cost? Lancet 2014, Published Online May 20, 2014.

84. Chetty T, Naidu K, Newell M: A systematic review of HIV-free survival by feeding practices from birth to 18 months: World Health Organization. 2010.

doi:10.1186/1742-4755-11-S1-S4

Cite this article as: Lassi et al:: Essential interventions for child health. Reproductive Health 2014 11(Suppl 1):S4.

\section{Submit your next manuscript to BioMed Central and take full advantage of:}

- Convenient online submission

- Thorough peer review

- No space constraints or color figure charges

- Immediate publication on acceptance

- Inclusion in PubMed, CAS, Scopus and Google Scholar

- Research which is freely available for redistribution

Submit your manuscript at www.biomedcentral.com/submit
Biomed Central 